\title{
Analysis of a slow-growing line reveals wide genetic variability of carcass and meat quality-related traits
}

Marie Chabault ${ }^{1}$, Elisabeth Baéza', Vérane Gigaud ${ }^{2}$, Pascal Chartrin ${ }^{1}$, Hervé Chapuis ${ }^{3}$, Maryse Boulay ${ }^{3}$, Cécile Arnould ${ }^{4,5,6,7}$, François D'Abbadie $^{8}$, Cécile Berri $^{1}$ and Elisabeth Le Bihan-Duval ${ }^{1 *}$

\begin{abstract}
Background: Slow-growing lines are widely used in France for the production of high quality free-range chickens. While such production is mainly dedicated to the whole carcass market, new prospects are opening up for the development of cuts and processed products. Whether the body composition and meat quality of slow-growing birds can be improved by selection has thus become an important issue. The genetic parameters of growth, body composition and breast meat quality traits were evaluated in relation to behaviour at slaughter in a large pedigree population including 1022 male and female slow-growing birds.

Results: The heritability coefficients $\left(h^{2}\right)$ of body weight and body composition traits varied from 0.3 to 0.5 . Abdominal fat percentage was genetically positively correlated with body weight but negatively correlated with breast muscle yield. The characteristics of the breast meat (i.e., post-mortem fall in $\mathrm{pH}$, colour, drip loss, shear-force and lipid content) were all heritable, with $\mathrm{h}^{2}$ estimates ranging from 0.18 to 0.48 . The rate and extent of the fall in $\mathrm{pH}$ were under different genetic control. Strong negative genetic correlations were found between the ultimate $\mathrm{pH}$ and the lightness, yellowness and drip loss of the meat. Wing flapping on the shackle line was significantly heritable and exhibited marked genetic correlations with the $\mathrm{pH}$ at $15 \mathrm{~min}$ post-slaughter and the redness of the meat. The genetic relationships between meat quality traits, body weight and body composition appeared slightly different between males and females.
\end{abstract}

Conclusion: This study suggested that there are a number of important criteria for selection on carcass and breast meat quality in slow-growing birds. Selection for reduced abdominal fatness and increased breast muscle yield should be effective as both traits were found to be highly heritable and favourably correlated. Substantial improvement in meat quality could be achieved by selection on ultimate $\mathrm{pH}$ which was highly heritable and strongly correlated with the colour and water-holding capacity of the meat. Moreover, this study revealed for the first time that the behaviour at slaughter is partly genetically determined in the chicken.

Keywords: Chicken, Slow-growing line, Meat quality, Behaviour at slaughter, Genetic parameters

\footnotetext{
* Correspondence: Elisabeth.Duval@tours.inra.fr

${ }^{1}$ Institut National de la Recherche Agronomique (INRA), UR83 Recherches

Avicoles, F-37380, Nouzilly, France

Full list of author information is available at the end of the article
} 


\section{Background}

The production of Label Rouge chicken began in France in the sixties, with the breeding of slow-growing lines well adapted to free range conditions and slaughtered at a more mature age (a minimum of 81 days) than conventional fast-growing lines (usually slaughtered between 35 and 42 days) [1,2]. It has been shown that the tenderness and juiciness of the meat decreases while flavour intensity increases when birds get older [3-7]. The higher sensorial quality of the meat and the strict regulations applied to the rearing conditions (low density, free access to outdoors, etc.) of Label Rouge chickens have contributed to the success of this product which is now extensively present in the whole carcass market in France (56\% of the market in 2011). However, the market share of Label Rouge chicken for cuts and processed products is still limited (11\% of cuts in 2011). In the long term this could become critical for the maintenance of such alternative products since there is increased consumption of cuts and processed products in most developed countries compared to whole carcasses. In order to estimate to what extent Label Rouge chickens could be adapted by selection to these market demands, we evaluated the genetic parameters of breast meat quality traits in relation to body weight and body composition in a slow-growing line. As a phenotypic relationship between the behaviour of these birds at slaughter and breast meat quality traits had previously been observed [8], the genetic relationships between these traits were also evaluated.

\section{Methods}

\section{Animals}

The birds originated from a slow-growing line selected by the SASSO breeding company (Sabres, France) since 1994. Birds were naked-neck chickens with yellow shanks. A large pedigree population was constituted of around 1022 male and female birds originating from 10 sires and 100 dams. Birds were reared in three successive batches (mixed sex) under similar free-range conditions. They had access to an outdoor area after 6 weeks of age. The bird density in the poultry house was 11 chickens per $\mathrm{m}^{2}$, and outside it was 2 chickens per $\mathrm{m}^{2}$ as required by the French legislation on Label Rouge production. Chickens were fed ad libitum, first with a starting diet from day 0 to 21 (Metabolisable Energy: $2740 \mathrm{kcal} / \mathrm{kg}$, Proteins: $201.9 \mathrm{~g} / \mathrm{kg}$, Lysine: $10.9 \mathrm{~g} / \mathrm{kg}$, Methionine: 4.7 $\mathrm{g} / \mathrm{kg}$ ), then with a growing diet from day 22 to 56 (Metabolisable Energy: $2863 \mathrm{kcal} / \mathrm{kg}$, Proteins: $169.5 \mathrm{~g} / \mathrm{kg}$, Lysine: $9.4 \mathrm{~g} / \mathrm{kg}$, Methionine: $3.9 \mathrm{~g} / \mathrm{kg}$ ), followed by a finishing diet from day 57 to 84 (Metabolisable Energy: $2930 \mathrm{kcal} / \mathrm{kg}$, Proteins: $159.5 \mathrm{~g} / \mathrm{kg}$, Lysine: $7.9 \mathrm{~g} / \mathrm{kg}$, Methionine: $3.7 \mathrm{~g} / \mathrm{kg}$ ). At 3, 6 and 9 weeks of age, birds were individually weighed and then at 12 weeks of age, birds were weighed and slaughtered after 7 hours' feed withdrawal. Birds did not undergo transport before they were slaughtered in the experimental slaughter plant (INRA, Pôle d'Expérimentation Avicole de Tours, F37380 Nouzilly, France). Duration of wing flapping (WF) on the shackle line was individually measured as previously described by Debut et al. [9]. Before sacrificing by ventral neck cutting, birds were electrically stunned (120 $\mathrm{Hz} \mathrm{AC,} 80 \mathrm{~mA} /$ bird, $5 \mathrm{~s}$ ) in a water bath, bled for $3 \mathrm{~min}$, and scalded at $51^{\circ} \mathrm{C}$ for $3 \mathrm{~min}$. After removal of the gut, whole carcasses were air chilled (airflow of $7 \mathrm{~m}^{3} / \mathrm{s}$ ) and stored at $2^{\circ} \mathrm{C}$ until the next day.

\section{Carcass and meat characteristics}

At 15 min post-mortem, the $\mathrm{pH}\left(\mathrm{pH}_{15}\right)$ was measured in the right Pectoralis major muscle as described by Berri et al. [8]. Samples of Pectoralis major muscle (about 60 g) were frozen at $-20^{\circ} \mathrm{C}$ for lipid determination. After thawing for $12 \mathrm{~h}$ at $4^{\circ} \mathrm{C}$, samples were ground and intramuscular fat content (IMF) was measured by nearinfrared spectroscopy on a Nirflex N-500 (Buchi, Rungis, France) as described by Chartrin et al. [10].

Carcasses were dissected $24 \mathrm{~h}$ post-mortem and the left breast meat (Pectoralis major plus minor), abdominal fat and leg weights were measured as described by Marche [11]. Yields were also calculated as percentages of body weight at slaughter. All measurements of meat quality were performed on the left Pectoralis major muscle. At $24 \mathrm{~h}$ post-mortem, the $\mathrm{pH}(\mathrm{pHu})$ was measured by direct insertion of the electrode in the muscle. Colour was measured on the upper ventral side of the muscle by using a Miniscan Spectrocolorimeter (Hunterlab, Reston, VA, USA). Colour was measured by the CIE$\mathrm{LAB}$ trichromatic system according to lightness $\left(\mathrm{L}^{*}\right)$, redness $\left(\mathrm{a}^{*}\right)$ and yellowness $\left(\mathrm{b}^{*}\right)$ values. The water holding capacity of meat was estimated by measuring drip loss of the raw meat after storage. The breast Pectoralis major muscle was weighed $24 \mathrm{~h}$ postmortem and immediately placed in a plastic bag, hung from a hook, and stored at $2^{\circ} \mathrm{C}$ for $5 \mathrm{~d}$. After hanging, each sample was wiped with absorbent paper and weighed again. The difference in weight corresponded to the drip loss and was expressed as the percentage of the initial muscle weight. After drip-loss evaluation, each muscle sample was vacuum-packed, cooked in a water-bath at $85^{\circ} \mathrm{C}$ for $15 \mathrm{~min}$, and cooled in crushed ice for $10 \mathrm{~min}$. After cooling, the sample was unpacked then wiped with absorbent paper. The texture of cooked meat was evaluated with a Warner Bratzler shear test according to the recommendations of Pettracci and Baeza [12]. The meat was sheared using a single shear blade, with a triangular shaped hole, placed on an Instron Universal Testing Instrument (Instron 5543, Guyancourt, France). Blade thickness was $1.1 \mathrm{~mm}$, the height and width at the base 
of the triangle were 52 and $61 \mathrm{~mm}$, respectively, and the rate of travel of the blade was $80 \mathrm{~mm} / \mathrm{min}$. Three adjacent strips of meat were cut from the medial portion of the P. major muscle so that the cross-section measured $10 \times 10 \mathrm{~mm}$ and the muscle fibers ran parallel to the length of the axis for $30 \mathrm{~mm}$. The samples were sheared at a right angle to the fibre axis. The parameter measured was the maximum force $(\mathrm{N})$ recorded.

\section{Estimation of the genetic parameters}

Descriptive statistics were calculated by the UNIVARIATE procedure of SAS software [13]. The dataset analysed included a total of 1022 observations for growth, body composition, breast meat quality traits and behaviour at slaughter. Heritability estimates and genetic correlations were computed in multitrait analyses by the Wombat software [14] using the REstricted Maximum Likelihood methodology and an animal model. This software accommodates high dimension issues with strongly correlated traits through reduced rank analyses. The model included the fixed effects of hatch and sex, the direct genetic effect of the animal and the environmental maternal effect in the case of body weight measured at 3, 6 and 9 weeks. Separate analyses by sex were also performed according to the same model but without sex effect. Approximate sampling errors of variance-covariance components were derived at convergence from the inverse of the average information matrix. Sampling errors of heritabilities or correlations were derived by first approximating the function by its first order Taylor series expansion, and then computing the variance of the latter. Five generations of ancestors were considered in the pedigree which included a total of 1489 animals. The distribution of wing flapping duration could not be considered as Gaussian. It was therefore classified in three categories, 1 when the bird did not flap ( $\mathrm{N}=446), 2$ when WF duration was less than 9 $\mathrm{s}(\mathrm{N}=248)$ and 3 when WF duration was between 9 and $36 \mathrm{~s}(\mathrm{~N}=248)$. The heritability of WF and the genetic correlations with continuous traits were estimated after a series of two-trait analyses using a threshold model with an animal effect using TM software based upon Gibbs Sampling and developed by A. Legarra (INRA, Station d'Amélioration Génétique des Animaux, F-31326 Castanet-Tolosan Cédex).

\section{Results}

\section{Phenotypic variability}

Except for WF, the distribution of the traits analyzed was close to normal. As shown in Table 1, the coefficient of variation $(\mathrm{CV})$ for body weight in the whole population remained fairly stable with age whereas it decreased when males and females were considered separately. CV for body weight at 12 weeks was about two-fold lower within each sex than in the whole population. The CV

Table 1 Body weight, body composition and meat quality-related traits

\begin{tabular}{|c|c|c|c|c|c|c|c|c|c|c|c|c|c|c|c|}
\hline & \multicolumn{5}{|c|}{ Males + Females } & \multicolumn{5}{|c|}{ Males } & \multicolumn{5}{|c|}{ Females } \\
\hline & $\mathbf{N}$ & Mean & CV (\%) & Min. & Max. & $\mathbf{N}$ & Mean & CV (\%) & Min. & Max. & $\mathbf{N}$ & Mean & CV (\%) & Min. & Max. \\
\hline \multicolumn{16}{|c|}{ body weight and body composition } \\
\hline BW3 (g) & 1022 & 415 & 14.4 & 234 & 603 & 515 & 432 & 14.4 & 234 & 603 & 507 & 397 & 12.8 & 247 & 545 \\
\hline BW6 (g) & 1006 & 1127 & 12.8 & 710 & 1523 & 508 & 1208 & 11.1 & 749 & 1523 & 498 & 1045 & 9.7 & 710 & 1373 \\
\hline BW9 (g) & 1000 & 1825 & 13.4 & 1193 & 2478 & 503 & 2006 & 9.4 & 1341 & 2478 & 497 & 1642 & 8.1 & 1193 & 2089 \\
\hline BW12 (g) & 958 & 2678 & 16.3 & 1750 & 3852 & 473 & 3052 & 8.8 & 2188 & 3852 & 485 & 2314 & 8.5 & 1750 & 2842 \\
\hline BMY (\%) & 910 & 16.5 & 8.0 & 12.1 & 21.7 & 450 & 16.2 & 7.3 & 12.1 & 19.9 & 460 & 16.8 & 7.9 & 12.9 & 21.7 \\
\hline AFP (\%) & 914 & 4.0 & 39.1 & 0.6 & 8.6 & 451 & 3.2 & 42.9 & 0.6 & 8.1 & 463 & 4.9 & 26.1 & 0.6 & 8.6 \\
\hline LEGP (\%) & 912 & 25.7 & 5.0 & 21.4 & 30.8 & 452 & 26.4 & 4.1 & 23.4 & 30.1 & 460 & 25.0 & 5.1 & 21.4 & 30.8 \\
\hline \multicolumn{16}{|c|}{ meat quality traits } \\
\hline $\mathrm{pH} 15$ & 921 & 6.61 & 3 & 5.98 & 7.03 & 458 & 6.62 & 2.7 & 5.98 & 6.97 & 463 & 6.6 & 3.3 & 5.98 & 7.03 \\
\hline $\mathrm{pHu}$ & 931 & 5.80 & 1.9 & 5.42 & 6.17 & 459 & 5.81 & 1.9 & 5.45 & 6.17 & 472 & 5.78 & 1.8 & 5.42 & 6.1 \\
\hline$L^{*}$ & 935 & 47.5 & 6.2 & 37.0 & 55.7 & 464 & 46.9 & 6.4 & 37.0 & 55.5 & 471 & 48.1 & 5.7 & 41.4 & 55.7 \\
\hline$a^{*}$ & 940 & -1.5 & 66 & -4.9 & 2.3 & 466 & -1.3 & 77.5 & -4.9 & 2.3 & 474 & -1.7 & 54.6 & -4.1 & 1.6 \\
\hline$b^{*}$ & 935 & 8.5 & 17 & 4.7 & 14.7 & 464 & 8.3 & 18.5 & 4.7 & 14.7 & 471 & 8.7 & 15.5 & 5 & 12.9 \\
\hline DL (\%) & 909 & 1.6 & 38.1 & 0.2 & 3.9 & 449 & 1.4 & 37.5 & 0.2 & 3.6 & 460 & 1.8 & 35.0 & 0.22 & 3.9 \\
\hline $\mathrm{SF}\left(\mathrm{N} / \mathrm{cm}^{2}\right)$ & 924 & 18.7 & 24.6 & 10.8 & 48.8 & 455 & 18.4 & 21.9 & 11.1 & 43.5 & 469 & 19.1 & 26.7 & 10.8 & 48.8 \\
\hline IMF (\%) & 693 & 1.0 & 22.1 & 0.6 & 2.1 & 340 & 1.0 & 23.9 & 0.6 & 2.1 & 353 & 1.1 & 20.5 & 0.6 & 2.0 \\
\hline
\end{tabular}

BW3 = Body weight at 3 weeks; BW6 = Body weight at 6 weeks; BW9 = Body weight at 9 weeks; BW12 = Body weight at 12 weeks.

$\mathrm{BMY}=$ Breast meat yield; AFP = Abdominal fat percentage; LEGP = Leg percentage; $\mathrm{pH} 15=\mathrm{pH}$ at $15 \mathrm{~min}$ post-mortem; $\mathrm{pHu}=\mathrm{ultimate} \mathrm{pH}$.

$\mathrm{L}^{*}=$ lightness; $\mathrm{a}^{*}=$ redness; $\mathrm{b}^{*}=$ yellowness; $\mathrm{DL}=$ drip loss; $\mathrm{SF}=$ shear force; IMF = Intramuscular fat content. 
for breast meat yield was more moderate, while it was quite high for the percentage of abdominal fat especially in males. In contrast, the variation for percentage of leg was limited for both sexes (4.1 to 5.1 ). The CV for early and ultimate $\mathrm{pH}$ values was low (from 1.9 to $3 \%$ ). The coefficients of variation for the other meat quality traits varied considerably and were relatively small for lightness, moderate for yellowness, shear force and intramuscular fat content but quite high for drip loss and redness of the meat.

A significant effect of sex was found on all the traits except pH15: as expected, males were heavier than females as early as 3 weeks and throughout the rearing period $(\mathrm{p}<0.0001)$. The females were fattier at slaughter age $(p<0.0001)$ and had a slightly higher breast meat yield $(\mathrm{p}<0.0001)$ and lower percentage of leg $(\mathrm{p}<0.0001)$ than the males. Significant differences were also observed in meat characteristics: the meat of females had a slightly lower $\mathrm{pHu}(\mathrm{p}<0.0001)$ and redness $(p<0.0001)$ than the males but a higher shear force $(p<0.02)$, drip loss $(p<0.0001)$, lightness $(p<0.0001)$ and yellowness $(p<0.0001)$. Lipid content of the breast meat was slightly higher for females than for males $(\mathrm{p}<0.005)$.

\section{Heritability estimates and genetic correlations in the whole population \\ Body weight and body composition traits}

Heritability of body weight increased with age and ranged between 0.31 at 3 weeks to 0.46 at 12 weeks (Table 2). Genetic correlations between the measurements of body weight at the different ages were all positive and high when the ages were close (0.8-0.94) but more moderate between the early and the final body weight (only 0.50 between BW3 and BW12). Heritability for body composition traits (BMY, AFP, LEGP) was high (between 0.43 and 0.53 ). AFP was genetically positively correlated with body weight at the different ages but negatively correlated with BMY.

\section{Meat quality-related traits}

Heritability of meat quality related traits varied between 0.18 (for IMF) to 0.48 (for $\mathrm{pHu}$ ). $\mathrm{pH} 15$ and $\mathrm{pHu}$ were not genetically correlated (rg of -0.09). Significant genetic correlations were revealed between the fall in $\mathrm{pH}$ and meat characteristics: the greater the early rate of fall in $\mathrm{pH}$ the redder, the less tender the breast meat ( $\mathrm{rg}$ of -0.51 between $\mathrm{pH} 15$ and $\mathrm{a}^{*}$, of -0.44 between $\mathrm{pH} 15$ and $\mathrm{SF}$ ), but the lower the ultimate $\mathrm{pH}$, the lighter, the more yellow and the more exudative the meat $(\mathrm{rg}$ of -0.83 , -0.53 and -0.68 between $\mathrm{pHu}$ and $\mathrm{L}^{*}, \mathrm{~b}^{*}$ and $\mathrm{DL}$, respectively). Significant positive genetic correlations were consistently found between $L^{*}, b^{*}$ and DL of the meat $(0.47-0.64)$. The results also revealed positive genetic correlations between the intramuscular fat content and lightness ( $\mathrm{rg}$ of 0.42 ) as well as the shear force ( $\mathrm{rg}$ of $0.57)$ of the meat.

\section{Genetic correlations between growth, body composition and meat quality-related traits}

The genetic correlations between body weight and body composition and the meat quality traits were generally low to moderate. However, meat redness exhibited a negative correlation with body weight $(-0.42)$ and AFP $(-0.46)$. AFP was also negatively related to yellowness ( $\mathrm{rg}$ of -0.43 ) and BMY to $\mathrm{pH} 15$ ( $\mathrm{rg}$ of -0.41 ). A marked positive genetic correlation was observed between LEGP and SF ( $r g$ of +0.62$)$.

\section{Behaviour at slaughter and meat quality}

The estimated heritability of duration of wing flapping was $0.41 \pm 0.09$, with low to moderate genetic correlations (0.04-0.20 in absolute value) with BW12, BMY, AFP, LEGP, pHu, L*, b*, DL, SF, and IMF. By contrast, significant genetic correlations were found between WF and $\mathrm{pH} 15$ as well as $\mathrm{a}^{*}$, estimates being $-0.71 \pm 0.11$ and $0.52 \pm 0.15$, respectively.

\section{Heritability estimates and genetic correlations according to sex}

The genetic parameters for male and female traits are reported in Additional file 1: Table S1 and Additional file 1: Table S2.

\section{Body weight and body composition traits}

Heritability of BW9, BW12, and BMY was higher in females (from 0.46 to 0.60 ) than in males (from 0.29 to 0.39) while it was the opposite for AFP. However, standard errors were greater than in the whole population, which was to be expected as the sample size was lower. The positive genetic correlation between body weight at the different ages and AFP was stronger in the males (between 0.43 and 0.60) than in the females (between 0.16 and $0.35, \mathrm{NS}$ ), while the negative genetic correlation between AFP and BMY was more marked in the females $(-0.57)$ than in the males $(-0.38, \mathrm{NS})$.

\section{Meat quality in relation to body weight and body composition}

Heritability of meat quality traits was similar in both sexes, except for L*, DL and IMF for which it was higher in the males $(0.55,0.43$, and 0.25 respectively) than in the females $(0.45,0.31$, and 0.16 respectively). Strong negative genetic correlations between body weight and AFP and meat redness $\left(\mathrm{a}^{*}\right)$ were observed in males (around -0.75) whereas they were much lower and nonsignificant in females (between -0.28 and 0 ). As in the whole population, a negative genetic correlation between pH15 and BMY was observed in both the males $(-0.52)$ 
Table 2 Heritability estimates (on the diagonal) and genetic correlations (above the diagonal) for body weight, body composition and meat quality traits in the whole population

\begin{tabular}{|c|c|c|c|c|c|c|c|c|c|c|c|c|c|c|c|}
\hline & BW3 & BW6 & BW9 & BW12 & BMY & AFP & LEGP & pH15 & $\mathrm{pHu}$ & $L^{*}$ & $a^{*}$ & $\mathbf{b}^{*}$ & $\mathrm{DL}$ & SF & IMF \\
\hline BW3 & $0.31 \pm 0.09$ & $0.80 \pm 0.08^{*}$ & $0.7 \pm 0.10$ & $0.50 \pm 0.15$ & $0.16 \pm 0.20$ & $0.45 \pm 0.17$ & $0.16 \pm 0.19$ & $0.10 \pm 0.21$ & $-0.03 \pm 0.18$ & $0.13 \pm 0.19$ & $-0.41 \pm 0.18$ & $-0.18 \pm 0.21$ & $-0.07 \pm 0.21$ & $0.15 \pm 0.22$ & $0.33 \pm 0.24$ \\
\hline BW6 & & $0.31 \pm 0.07$ & $0.94 \pm 0.03$ & $0.80 \pm 0.08$ & $0.28 \pm 0.19$ & $0.46 \pm 0.16$ & $0.08 \pm 0.19$ & $-0.10 \pm 0.21$ & $-0.04 \pm 0.18$ & $0.04 \pm 0.19$ & $-0.27 \pm 0.19$ & $-0.32 \pm 0.21$ & $-0.01 \pm 0.21$ & $0.03 \pm 0.23$ & $0.29 \pm 0.25$ \\
\hline BW9 & & & $0.45 \pm 0.08$ & $0.93 \pm 0.03$ & $0.30 \pm 0.17$ & $0.45 \pm 0.14$ & $0.16 \pm 0.18$ & $-0.06 \pm 0.19$ & $-0.12 \pm 0.17$ & $0.15 \pm 0.17$ & $-0.42 \pm 0.16$ & $-0.28 \pm 0.19$ & $0.03 \pm 0.20$ & $0.08 \pm 0.21$ & $0.35 \pm 0.23$ \\
\hline BW12 & & & & $0.46 \pm 0.09$ & $0.22 \pm 0.17$ & $0.38 \pm 0.15$ & $0.20 \pm 0.17$ & $-0.11 \pm 0.18$ & $-0.26 \pm 0.15$ & $0.24 \pm 0.16$ & $-0.42 \pm 0.16$ & $-0.20 \pm 0.18$ & $0.01 \pm 0.19$ & $0.18 \pm 0.20$ & $0.34 \pm 0.22$ \\
\hline BMY & & & & & $0.46 \pm 0.12$ & $-0.42 \pm 0.14$ & $0.17 \pm 0.17$ & $-0.41 \pm 0.18$ & $0.13 \pm 0.17$ & $-0.19 \pm 0.17$ & $0.12 \pm 0.18$ & $0.06 \pm 0.19$ & $0.20 \pm 0.19$ & $-0.08 \pm 0.21$ & $-0.29 \pm 0.23$ \\
\hline AFP & & & & & & $0.53 \pm 0.14$ & $-0.24 \pm 0.16$ & $0.33 \pm 0.17$ & $0.15 \pm 0.16$ & $0.02 \pm 0.17$ & $-0.46 \pm 0.15$ & $-0.43 \pm 0.16$ & $-0.21 \pm 0.19$ & $-0.12 \pm 0.20$ & $0.32 \pm 0.21$ \\
\hline LEGP & & & & & & & $0.43 \pm 0.08$ & $-0.08 \pm 0.19$ & $-0.18 \pm 0.17$ & $0.13 \pm 0.17$ & $-0.13 \pm 0.18$ & $-0.14 \pm 0.19$ & $0.04 \pm 0.19$ & $0.62 \pm 0.16$ & $0.25 \pm 0.23$ \\
\hline pH15 & & & & & & & & $0.34 \pm 0.08$ & $-0.09 \pm 0.18$ & $0.16 \pm 0.17$ & $-0.51 \pm 0.14$ & $0.04 \pm 0.20$ & $-0.24 \pm 0.19$ & $-0.44 \pm 0.17$ & $-0.13 \pm 0.24$ \\
\hline $\mathrm{pHu}$ & & & & & & & & & $0.48 \pm 0.08$ & $-0.83 \pm 0.07$ & $0.15 \pm 0.17$ & $-0.53 \pm 0.14$ & $-0.68 \pm 0.12$ & $-0.26 \pm 0.18$ & $-0.03 \pm 0.21$ \\
\hline$L^{*}$ & & & & & & & & & & $0.44 \pm 0.10$ & $-0.28 \pm 0.16$ & $0.51 \pm 0.14$ & $0.64 \pm 0.13$ & $0.34 \pm 0.19$ & $0.42 \pm 0.20$ \\
\hline$a^{*}$ & & & & & & & & & & & $0.39 \pm 0.10$ & $0.05 \pm 0.19$ & $0.03 \pm 0.19$ & $0.22 \pm 0.19$ & $-0.20 \pm 0.24$ \\
\hline$b^{*}$ & & & & & & & & & & & & $0.30 \pm 0.11$ & $0.47 \pm 0.18$ & $0.02 \pm 0.22$ & $-0.33 \pm 0.24$ \\
\hline $\mathrm{DL}$ & & & & & & & & & & & & & $0.30 \pm 0.12$ & $0.10 \pm 0.22$ & $-0.04 \pm 0.25$ \\
\hline SF & & & & & & & & & & & & & & $0.22 \pm 0.08$ & $0.57 \pm 0.21$ \\
\hline IMF & & & & & & & & & & & & & & & $0.18 \pm 0.07$ \\
\hline
\end{tabular}

BW3 = Body weight at 3 weeks; BW6 = Body weight at 6 weeks; BW9 = Body weight at 9 weeks; BW12 = Body weight at 12 weeks.

$\mathrm{BMY}=$ Breast meat yield; AFP = Abdominal fat percentage; LEGP = Leg percentage; $\mathrm{pH} 15=\mathrm{pH}$ at 15 min post-mortem; $\mathrm{pHu}=$ ultimate $\mathrm{pH}$.

$\mathrm{L}^{*}=$ lightness; $\mathrm{a}^{*}=$ redness; $\mathrm{b}^{*}=$ yellowness; $\mathrm{DL}=$ drip loss; $\mathrm{SF}=$ shear force; $\mathrm{IMF}=$ Intramuscular fat content. * Significant genetic correlations are in bold. 
and females $(-0.43)$. The genetic correlations between $L^{*}$ and $\mathrm{pHu}$ and between $\mathrm{L}^{*}$ and DL were lower (in absolute value) in the females $(-0.78$ and 0.36 , respectively) than in the males $(-0.90$ and 0.84 , respectively). Breast meat SF and LEGP remained positively correlated for both sexes ( 0.72 and 0.65 for males and females, respectively) whereas the correlation between SF and $L^{*}$ was significant in the females (0.57) but not in the males $(0.10)$.

\section{Discussion}

Because the minimal age of the animals required by the "label" organisation is 81 days, the "label" strains have to be chosen from a specific list which only contains slowgrowing lines. Independently of the characteristics associated with reproduction, the selection of these lines includes several traits associated with the quality of the final product such as body weight (mainly to avoid genetic drift), body conformation (improvement of the breast angle and a better meat and bone yield), fattening (which has to be maintained rather low) as well as the thickness of the skin and the feed conversion $[1,2]$. This study was the first one dealing with the genetic aspects of carcass and meat quality related traits in a "label" strain. The small number of sire families considered in this study was a limitation regarding the accuracy of the genetic parameter estimates, especially the genetic correlations, which should be confirmed on a larger data set in order to find out the most relevant criteria of selection. However, one can underline the fact that several estimated correlations were consistent with previous ones obtained on conventional broiler lines, showing that we may be confident about the sign and the strength of these relationships.

Wide genetic variability for body weight and body composition traits was found in the slow-growing line used in the present study. It was associated with a fairly extensive phenotypic variability, especially for traits such as AFP. Whereas weight gain is not desirable in such a line, selection for reduced AFP and increased BMY could be valuable particularly since both traits are highly heritable and favourably (i.e. negatively) correlated, as already reported in several other chicken lines $[15,16]$. Improving body composition could have important economic benefits due to the expected gain in feed efficiency and cut yields. However, whether meat quality might be impaired is an important issue which may be addressed by estimating the genetic correlations between body composition and meat quality traits. According to our results, selection for decreasing carcass fatness by reducing AFP should not lead to any significant change in IMF, which is known to influence sensorial characteristics of the meat such as juiciness and flavour [7]. Similarly, the studies by Chen et al. [17] and Zerehdaran et al. [15] failed to demonstrate any significant correlation between the deposition of abdominal fat and that of intramuscular fat in breast muscle, whereas a positive genetic correlation was reported between abdominal and subcutaneous fat. On the other hand, our results indicated that selection for lower carcass fatness should increase the intensity of the red and yellow colour of breast meat, especially in males in which a strong genetic link between AFP and body weight was also found. Moreover, selection for greater muscle development of the bird, including the breast and leg, could have an impact on meat characteristics as revealed by the negative genetic correlation between BMY and $\mathrm{pH} 15$ and the positive correlation between LEGP and SF. Although some sensory tests would be needed, these genetic correlations do not support a marked deleterious effect of selection for higher breast meat yield and lower abdominal fatness on the sensorial quality of the meat. Moreover, no genetic correlation was found with the ultimate $\mathrm{pH}$, a factor determining the technological quality of meat [8].

The genetic parameters of measurements of the technological quality of the meat (such as the $\mathrm{pH}$, colour, drip loss or shear-force) were evaluated for the first time in a slow-growing line. As in previous studies on intermediate and fast-growing chickens [18,19], genetics explained a large part of the variability of these traits, with heritability estimates ranging from 0.22 to 0.48. Also in this slow-growing line, the ultimate $\mathrm{pH}$ of the meat was highly heritable and strongly genetically correlated with the colour and water-holding capacity of the meat. Acid meat defects, characterized by a low ultimate $\mathrm{pH}$, pale colour and low water-holding capacity, have become a major problem in the United States and Europe where their frequency ranges between 5\% and $47 \%$ within a flock [20]. A survey undertaken between 2007 and 2010 in various French slaughter plants showed that it affected not only standard but also alternative products. When compared with intermediate or fast-growing chickens used for standard production, the slow-growing birds used for Label Rouge production had the lowest ultimate $\mathrm{pH}$ [21], which was consistent with their higher glycogen reserve in breast muscle [9]. The incidence of meat exhibiting low $\mathrm{pH}(<5.7)$ was high in all types of production, but the highest proportion (around 50\%) occurred in the free-range Label-Rouge production. The present study indicates that substantial improvement of the technological quality of breast meat originating from slow-growing birds could be achieved by genetic selection on ultimate $\mathrm{pH}$.

As already observed in previous studies [18,19], the initial rate and the extent of decrease in $\mathrm{pH}$ are genetically independent. While ultimate $\mathrm{pH}$ was shown to be determined by the glycogen content of breast muscle $[19,22]$, strong phenotypic correlations were found between breast meat $\mathrm{pH}$ at 15 min post-mortem and duration of wing flapping on the shackle line [8]. Moreover, struggling activity after hanging was shown to be more 
intense and rapid in the slow-growing Label-Rouge line than in heavy or fast-growing lines [9]. We showed for the first time in poultry that this struggling activity is partly genetically determined. According to several studies performed in the context of animal welfare, hanging broilers in an inverted position is experienced as a stressful event [23] associated with increased plasma corticosterone concentrations [9,24]. Vigorous wing flapping is seen as an escape behaviour and an indicator of discomfort. It may be responsible for physical damage such as broken bones or dislocation [25] which may be painful for the animals and responsible for economic losses due to downgrading of carcasses or problems with portioning. As already shown at the phenotypic level [8], and confirmed by the present study at the genetic level, wing flapping also affected breast meat quality by hastening the fall in muscle $\mathrm{pH}$ and increasing the redness of the meat, probably because of higher blood flow in the muscles of flapping birds. In addition to improvements in slaughter equipment, this study suggests that the prevalence of wing flapping on the shackle line could be decreased by genetic selection, with positive effects on carcass and meat quality. However, as wing flapping does not entirely summarize bird welfare, the impact on other indicators of stress at slaughter and on the behaviour of birds during rearing should be investigated before any selection can be envisaged.

This study revealed that the genetic correlations between growth, body composition and meat quality traits can differ partially between males and females. As classically observed in the chicken [16], males exhibited a higher growth rate while the females were characterized by earlier development of breast muscle and abdominal fatness, showing that they appear physiologically more mature than males at a given age. Slight differences were also observed in the technological characteristics of the meat. The genetic correlation between the ultimate $\mathrm{pH}$ and the lightness of the meat was lower for females than for males. Higher growth rate, associated with greater abdominal fatness, led to a decrease in red colour of the meat in the males while it was not apparent in the females. Although more research is needed to elucidate the mechanisms and the genes relating growth and meat quality in both sexes, our findings suggest some practical recommendations. As males have higher body and breast muscle weight, they appear more appropriate for the cuts market, particularly since meat tenderness increases with muscle growth [19]. Females, which are smaller and have a slightly more acid, pale and exudative meat, would be more appropriate for the whole carcass market.

\section{Conclusion}

The results of this study suggest several relevant criteria for the selection of slow-growing birds in order to adapt their meat to the new market demands. However, such selection is currently made difficult by the fact that the birds have to be killed for the measurement of meat quality, and only sib selection, which is more costly and less efficient, can be applied. Research therefore has to be continued for molecular markers that can be used for the selection of carcass and meat quality- related traits in chickens.

\section{Additional file}

\begin{abstract}
Additional file 1: Table S1. Heritability estimates (on the diagonal) and genetic correlations (above the diagonal) for body weight, body composition and meat quality traits in males. Table S2 Heritability estimates (on the diagonal) and genetic correlations (above the diagonal) for body weight, body composition and meat quality traits in females.
\end{abstract}

\section{Competing interests}

The authors declare that they have no competing interests.

\section{Authors' contributions}

$M C, E B, V G, P C, C A, C B, E L B D$ contributed to the experimental design. $P C$ and EB performed the lipid measurements. $M C, H C, M B$ and ELBD performed the genetic analyses. All authors read and approved the final manuscript.

\section{Acknowledgements}

We thank the PEAT experimental unit (UE 1295 Pôle Expérimental Avicole de Tours, INRA, Nouzilly, France) for bird management. The study was carried out with the financial support of the "Conseil Régional du Centre" (Quanutecvol project, 2009-2011) and FranceAgrimer.

\section{Author details}

${ }^{1}$ Institut National de la Recherche Agronomique (INRA), UR83 Recherches Avicoles, F-37380, Nouzilly, France. 'Institut Technique de I'Aviculture (ITAVI), Centre INRA de Tours, F-37380, Nouzilly, France. ${ }^{3}$ Syndicat des Sélectionneurs Avicoles et Aquacoles Français (SYSAAF), Centre INRA de Tours, F-37380, Nouzilly, France. ${ }^{4}$ Institut National de la Recherche Agronomique (INRA), UMR85 Physiologie de la Reproduction et des Comportements, F-37380, Nouzilly, France. ${ }^{5}$ CNRS, UMR7247, F-37380, Nouzilly, France. ${ }^{6}$ Université François Rabelais de Tours, F-37041, Tours, France. ${ }^{7}$ IFCE, F-37380, Nouzilly, France. ${ }^{8}$ SASSO, F-40630, Sabres, France.

Received: 22 May 2012 Accepted: 18 October 2012

Published: 23 October 2012

\section{References}

1. Sauveur B: Les critères et facteurs de la qualité des poulets Label Rouge. INRA Prod. Anim 1997, 10:219-226.

2. Rémignon $\mathrm{H}$, Culioli J: Meat quality traits of French «Label » chickens. In Proceedings of the 12th European Symposium on the Quality of Poultry Meat: 25-29 September 1995. Spain: Zaragoza; 1995:145-150.

3. Nakamura R, Sekoguchi S, Sato Y: The contribution of intramuscular collagen to the tenderness of meat from chickens with different ages. Poultry Sci 1975, 54:1604-1612.

4. Yamashita C, Ishimoto Y, Mekada H, Ebisawa S, Murai I, Nonaka S: Studies on meat quality of broilers II: Influence of age of chickens on the meat taste. Japanese Poultry Science 1976, 13:14-19.

5. Sonayia EB, Ristic M, Klein WF: Effect of environmental temperature, dietary energy, age, sex on broiler carcase portions and palatability. Brit. Poultry Sci 1990, 31:121-128.

6. Touraille C, Kopp J, Valin C, Ricard FH: Qualité du poulet. 1. Influence de l'âge et de la vitesse de croissance sur les caractéristiques physico-chimiques et organoleptiques de la viande. Arch. Geflügelk 1981a, 45:69-76.

7. Touraille C, Ricard FH, Kopp J, Valin C, Leclercq B: Qualité du poulet. 2. Evolution en fonction de l'âge des caractéristiques physico-chimiques et organoleptiques de la viande. Arch. Geflügelk 1981b, 45:97-104. 
8. Berri C, Debut M, Santé-L'houtellier V, Arnould C, Boutten B, Sellier N, Baéza E, Jehl N, Jégo Y, Duclos MJ, Le Bihan-Duval E: Variations in chicken breast meat quality: implications of struggle and muscle glycogen content at death. Brit. Poultry Sci 2005, 46:572-579.

9. Debut M, Berri C, Arnould C, Santé-L'houtellier V, Guémené, Sellier N, Baéza E, Jehl N, Jégo Y, Beaumont C, Le Bihan-Duval E: Behavioural and physiological responses of three chicken breeds to pre-slaughter shackling and acute heat stress. Brit. Poultry Sci 2005, 46:527-535.

10. Chartrin P, Rousseau X, Gigaud V, Bastianelli D, Baéza E: Near-infrared reflectance spectroscopy for predicting lipid content in chicken breast meat. In Proceedings of the 13th WPSA European Poultry Conference: 23-27 August 2010. France: Tours; 2010:4p.

11. Marche G: La découpe anatomique et la dissection des volailles. Nouzilly (France): SYSAAF and INRA; 2000.

12. Petracci M, Baeza E: Harmonization of methodologies for the assessment of poultry meat quality features. Worlds Poult Sci J 2011, 67:137-151.

13. SAS Institute: SAS ${ }^{\circledR}$ Institute: Version 6. 4. Cary. NC, USA: SAS Institute Inc SAS Institute; 1999.

14. Meyer K: "WOMBAT" - Digging deep for quantitative genetic analyses by restricted maximum likelihood. In Proceedings of the 8th World Congress on Genetic Applied to Livestock Production: 13-18 August 2006. Brazil: Belo Horizonte; 2006.

15. Zerehdaran $\mathrm{S}$, Vereijken AL, van Arendonk JAM, van der Waaij EH: Estimation of genetic parameters for fat deposition and carcass traits in broilers. Poultry Sci 2004, 83:521-525.

16. Le Bihan-Duval E, Mignon-Grasteau S, Millet N, Beaumont C: Genetic analysis of a selection experiment on increased body weight and breast muscle weight as well as on limited abdominal fat weight. Brit. Poultry Sci 1998, 39:346-353.

17. Chen JL, Zhao GP, Zheng MQ, Wen J, Yang N: Estimation of genetic parameters for contents of intramuscular fat and Inosine- $5^{\prime}$ Monophosphate and carcass traits in Chinese Beijing-You chickens. Poultry Sci 2008, 87:1098-1104.

18. Le Bihan-Duval E, Berri C, Baéza E, Millet N, Beaumont C: Estimation of the Genetic Parameters of Meat Characteristics and of Their Genetic Correlations with Growth and Body Composition in an Experimental Broiler Line. Poultry Sci 2001, 80:839-843.

19. Le Bihan-Duval E, Debut M, Berri C, Sellier N, Santé-L'houtellier V, Jégo Y, Beaumont C: Chicken meat quality: genetic variability and relationship with growth and muscle characteristics. BMC Genet 2008, 9:53.

20. Petracci M, Bianchi M, Cavani C: The European perspective on pale, soft, exudative conditions in poultry. Poultry Sci 2009, 88:1518-1523.

21. Berri C, Le Bihan-Duval E, Gigaud V, Baéza E, Duclos MJ: Towards the identification of mechanisms underlying the variations of chicken meat processing ability. In Proceedings of the 13th WPSA European Poultry Conference: 23-27 August 2010. France: Tours; 2010:9p.

22. Berri C, Le Bihan-Duval E, Debut M, Santé-Lhoutellier V, Baeza E, Gigaud V, Jégo $Y$, Duclos $\mathrm{M}$ : Consequence of muscle hypertrophy on characteristics of Pectoralis major muscle and breast meat quality of broiler chickens. J Anim Sci 2007, 85:2005-2011.

23. Sparrey JM, Kettlewell PJ: Shackling of poultry: is it a welfare problem? World Poultry Sci. World Poultry Sci. J 1994, 50:167-176.

24. Kannan G, Mench JA: Influence of different handling methods and crating periods on plasma corticosterone concentrations in broilers. Brit. Poultry Sci 1996, 37:21-31.

25. Gregory NG, Wilkins $\sqcup$ : Broken bones in chickens: effects of stunning and processing in broilers. Brit. Poultry Sci 1990, 31:53-58.

doi:10.1186/1471-2156-13-90

Cite this article as: Chabault et al: Analysis of a slow-growing line reveals wide genetic variability of carcass and meat quality-related traits. BMC Genetics 2012 13:90.

\section{Submit your next manuscript to BioMed Central and take full advantage of:}

- Convenient online submission

- Thorough peer review

- No space constraints or color figure charges

- Immediate publication on acceptance

- Inclusion in PubMed, CAS, Scopus and Google Scholar

- Research which is freely available for redistribution

Submit your manuscript at www.biomedcentral.com/submit 